\title{
Prediction of clinical response to omalizumab in moderate-to-severe asthma patients using the change in total serum IgE level
}

\author{
Bohou Li $^{1 \#}$, Minyu Huang ${ }^{1 \#}$, Shuyu Huang ${ }^{1}$, Xiaoli Zeng ${ }^{1}$, Yafei Yuan ${ }^{1}$, Xianru Peng ${ }^{1}$, Wenqu Zhao ${ }^{1}$ \\ Yanmei Ye ${ }^{1}$, Changhui Yu ${ }^{1}$, Laiyu Liu ${ }^{1}$, Chunquan Ou ${ }^{2}$, Shaoxi Cai ${ }^{1}$, Haijin Zhao ${ }^{1}$ \\ ${ }^{1}$ Chronic Airways Diseases Laboratory, Department of Respiratory and Critical Care Medicine, Nanfang Hospital, Southern Medical University, \\ Guangzhou, China; ${ }^{2}$ Department of the Biostatistics, Guangdong Provincial Key Laboratory of Tropical Disease Research, School of Public Health, \\ Southern Medical University, Guangzhou, China \\ Contributions: (I) Conception and design: H Zhao, B Li; (II) Administrative support: H Zhao; (III) Provision of study materials or patients: B Li; (IV) \\ Collection and assembly of data: All authors; (V) Data analysis and interpretation: B Li, M Huang, S Huang; (VI) Manuscript writing: All authors; (VII) \\ Final approval of manuscript: All authors. \\ \#These authors contributed equally to this work. \\ Correspondence to: Haijin Zhao. Chronic Airways Diseases Laboratory, Department of Respiratory and Critical Care Medicine, Nanfang Hospital, \\ Southern Medical University, Guangzhou 510515, China. Email: zhjin@smu.edu.cn.
}

Background: Omalizumab (OMA) is an effective anti-immunoglobulin E (IgE) treatment for moderateto-severe asthma. However, predicting an individual's response is difficult. Monitoring change of total serum IgE may be useful for predicting the response to OMA. The purpose of this study was to determine if measuring the change in total $\mathrm{IgE}$ level could predict the response to OMA in patients with moderate-tosevere asthma.

Methods: This study included 25 patients (11 females and 14 males; mean age $=46.1$ years; mean prebronchodilator FEV1\% =67.8\%) with moderate-to-severe asthma. All patients were treated with OMA, and total $\mathrm{IgE}$ serum concentrations were measured at baseline before treatment (median baseline total serum $\mathrm{IgE}=210 \mathrm{IU} / \mathrm{mL}$ ) and at 4 weeks after beginning treatment. Patients were divided into responders (i.e., excellent or good response) and non-responders (i.e., moderate or poor response) using the global treatment effectiveness (GETE) response method after 16 weeks of treatment. The characteristics of responders and non-responders were compared, and receiver operating characteristic (ROC) curve analysis was used to determine the ability of change in $\mathrm{IgE}$ level to predict treatment response.

Results: There were 20 responders (80\%) and 5 non-responders (20\%), and responders demonstrated better improvements of asthma control test (ACT) and asthma control questionnaire (ACQ) scores, and reduction of oral corticosteroid use as compared with non-responders. Twenty-one patients had a total serum $\operatorname{IgE} 4$-week-to-baseline ratio $\geq 2$, and 20 of the patients responded to OMA. The area under the ROC curve (AUC) for baseline IgE level for predicting treatment response was 0.53 (95\% CI: 0.18-0.88), and that of the week $4 \mathrm{IgE}$ level was 0.69 (95\% CI: 0.42-0.96). Using a cutoff value of 2, the 4-week: baseline IgE ratio achieved the highest AUC of 0.87 (95\% CI: 0.64-1), with a sensitivity and specificity of $100 \%$ and $80 \%$, respectively, for predicting treatment response.

Conclusions: A total week 4 serum IgE level:baseline level ratio $\geq 2$ can predict the response to OMA in patients with moderate-to-severe asthma after 16 weeks of treatment with high likelihood. Monitoring changes of total IgE level in asthma patients treated OMA may be useful for predicting clinical response.

Keywords: Asthma; immunoglobulin E (IgE); omalizumab (OMA); treatment effectiveness

Submitted May 29, 2020. Accepted for publication Oct 23, 2020.

doi: $10.21037 /$ jtd-20-2073

View this article at: http://dx.doi.org/10.21037/jtd-20-2073

(C) Journal of Thoracic Disease. All rights reserved. 


\section{Introduction}

Immunoglobulin $\mathrm{E}(\mathrm{IgE})$ plays a central role in pathophysiological mechanisms of allergic reactions and bronchial airway inflammation (1-3). Based on this data, a recombinant humanized monoclonal anti- $\operatorname{IgE}$ antibody, omalizumab, was approved for the treatment of insufficiently controlled moderate-to-severe persistent IgEmediated allergic asthma (4). Omalizumab targets the Fc region of free serum $\mathrm{IgE}$, forms immune complexes, and reduces the serum level of free $\operatorname{IgE}(4)$. It also blocks allergic responses via the downregulation of the high affinity $\operatorname{IgE}$ receptor FceRI, which is present on inflammatory and structural cells, and by the inhibition of mast cell activation and the release of inflammatory factors by basophils (5-7). Omalizumab has been shown to reduce asthma-induced symptoms and exacerbations, and emergency department visits and hospitalizations (8-10). However, the Global Initiative for Asthma guidelines indicate that its cost is high, and that patient responses vary widely (4).

The dosage and frequency of omalizumab administration are calculated based on baseline total serum IgE level and bodyweight. However, baseline total serum IgE level does not dependably predict the response (11-13). It seems that free $\operatorname{IgE}$, rather than total $\operatorname{IgE}$, is closely related to response to omalizumab; however, it is difficult to monitor free serum $\operatorname{IgE}$ levels once omalizumab treatment is initiated. Furthermore, monitoring free $\mathrm{IgE}$ and omalizumab serum concentrations has not been shown to predict the clinical response or assist in deciding to continue or stop treatment (14).

Recently, baseline serum CXCL10 and interleukin (IL)-12 levels have been shown that they may predict severe asthmatics' responsiveness to omalizumab; unfortunately, levels of these cytokines are low and blood levels cannot be measured reliably (12). Thus, there are no reliable predictors of the response to omalizumab in patients with asthma (12-15).

A recent study showed that monitoring the change of total serum IgE level in patients with chronic spontaneous urticaria can predict the response to omalizumab (16). The study showed that a ratio of total serum IgE level at 4 weeks after beginning treatment: baseline level $\geq 2$ was associated with a high likelihood of adequate treatment response (16). Based on this finding, the purpose of this study was to determine if a change of total serum IgE level could predict the response to omalizumab in patients with moderate-tosevere asthma.
We present the following article in accordance with the $\operatorname{IgE}$ change predicts asthma patients' response to omalizumab reporting checklist (available at http://dx.doi. org/10.21037/jtd-20-2073).

\section{Methods}

\section{Patients}

Twenty-five patients with uncontrolled moderate-tosevere persistent asthma were recruited from March 2018 to December 2019, from the respiratory outpatient clinic at Southern Medical University, Nanfang Hospital (Guangzhou, China) (Figure 1). Moderate-to-severe persistent uncontrolled asthma is characterized by frequent daily symptoms or nocturnal awakenings and exacerbations, despite a minimum of 3 -step treatment $(4,17)$. Moderate asthma was defined as under complete control using 3-step treatment. Severe asthma was defined as controlled or uncontrolled even using 4 - or 5 -step treatment $(4,17)$. The diagnosis of asthma was based on physician observation of reversible airflow obstruction. Reversible airflow obstruction was defined as forced expiratory volume in $1 \mathrm{~s}$ (FEV1) increase from baseline $\geq 12 \%$ and FEV1 absolute value increase $\geq 200 \mathrm{~mL}$ after inhalation $400 \mu \mathrm{g}$ salbutamol. All patients were treated with omalizumab based on national (17) and international guidelines (4). The total serum IgE levels and bodyweight of all patients were within the parameters described in the omalizumab dosing table.

Exclusion criteria were current smoking, serious comorbidities including bronchiectasis, ABPA and lung cancer, respiratory tract infection or acute exacerbation within the past 4 weeks, and the possibility of pregnancy. This study was approved by the Hospital Ethics Committee (code number NFEC-2018-092). All patients provided written informed consent for participation in the study.

\section{Study design}

This was an open single-center, prospective study of consecutive cases. Two to 4 weeks before beginning omalizumab treatment (baseline), patients were seen to confirm they were appropriate candidates for omalizumab treatment, their remission stage, and to collect demographic data (Figure 1). Baseline data collected included current medications, comorbidities, fractional exhaled nitric oxide (FeNO), blood eosinophilic count and ratio, eosinophilic ratio in induced sputum, and serum vitamin $\mathrm{D}$ level. 


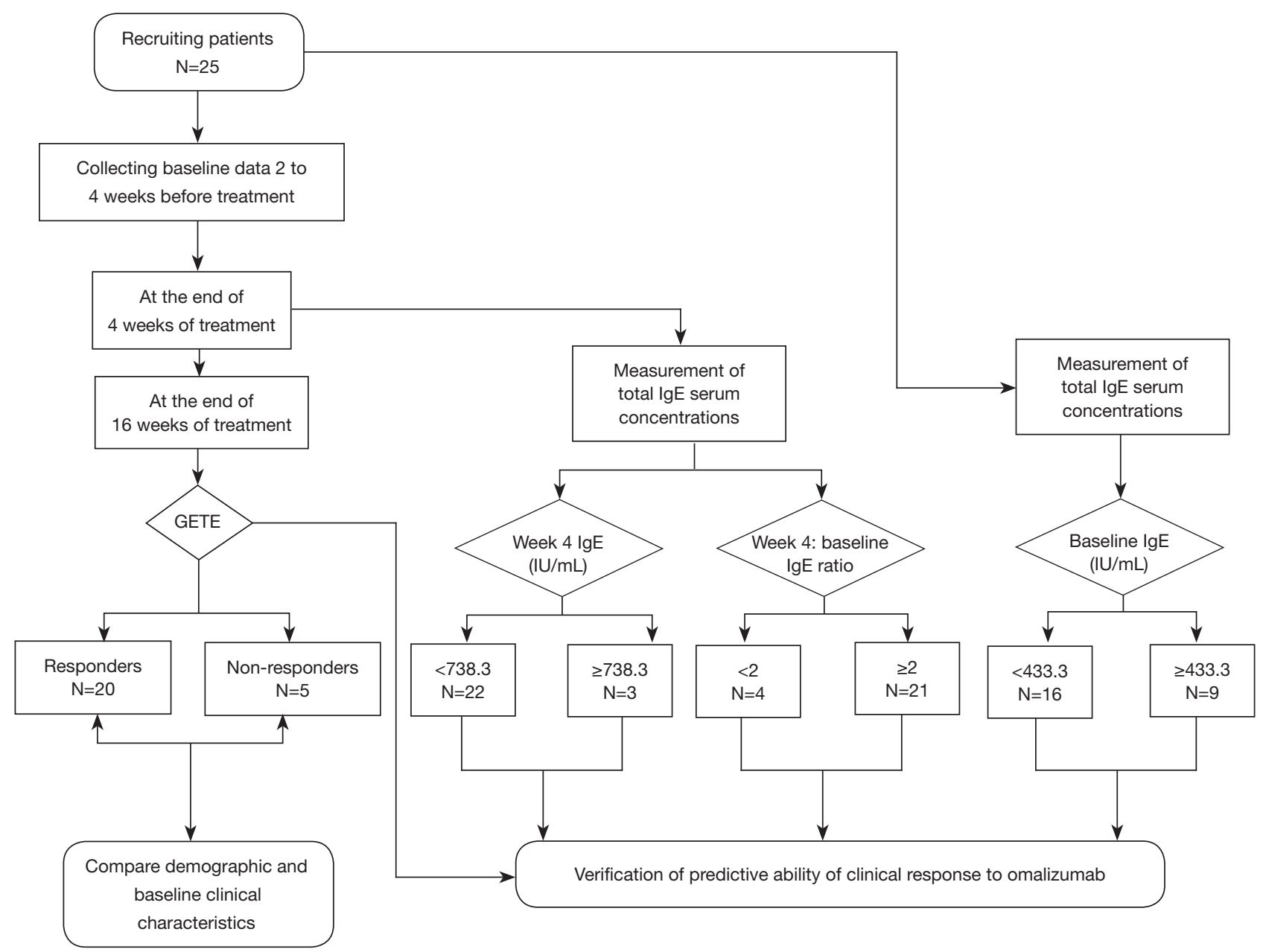

Figure 1 Flowchart of participants.

Twenty-three patients received monthly subcutaneous injections of omalizumab for a total of 16 weeks; two patients are injected every two weeks; the dosage was derived from the standard omalizumab dosing table. Patients received clinic visits prior to each injection, and at the end of the 16 weeks. Omalizumab effectiveness was evaluated after 16 weeks (4).

Total IgE serum concentrations were measured at baseline and at the end of week 4, prior to the second injection. Levels were measured using an electrochemical luminescence method (Roche, Germany), which is a commonly used method that measures both free and omalizumab-bound IgE. Serum samples were tested within 1 hour after collection. The ratio of week $4 \operatorname{IgE}$ level:baseline IgE level was calculated.

Other data collected at baseline and each followup visit included: pre-bronchodilator lung function (according to ATS/ERS(American Thoracic Society/ European Respiratory Society) criteria (18), Jaeger MasterScreen Body, Hoechberg, Germany), exhaled NO level according to ATS guidelines (Niox Mino, Aerocrine, Sweden), physician-assessed evaluation of global treatment effectiveness (GETE: excellent, good, moderate, poor, worsened) (19), and evaluation of asthma control with the asthma control questionnaire (ACQ) (20) and asthma control test (ACT) (21). The minimal clinically significant changes in ACQ and ACT scores are 0.5 and 3, respectively. Proper medication adjustment was permitted to improve a patient's asthma control.

\section{Statistical analysis}

Patients rated as good or excellent by GETE were considered to be responders, and demographic and clinical 
characteristics were compared between responders and non-responders. The Kolmogorov Smirnov test was used to determine whether continuous variables were normally distributed. Levene's test was used for the evaluation of homogeneity of variances. Continuous data (e.g., age) were presented as mean \pm standard deviation. Non-normally distributed variables (e.g., total $\mathrm{IgE}$ ) were presented as medians and interquartile ranges (IQR). Categorical data were presented as count and percentage. Continuous data were compared with the 2 -sample $t$-test and categorical data with the Fisher's exact test; non-normally distributed data were examined with the Mann Whitney $\mathrm{U}$ test.

Receiver operating characteristic (ROC) curve analyses were used to determine the predictive value of baseline $\mathrm{IgE}$ level, week $4 \operatorname{IgE}$ level, and the week 4: baseline $\operatorname{IgE}$ ratio could predict response to omalizumab. The maximized likelihood was used to identify cutoff values, and to calculate the sensitivity and specificity. The area under the ROC curve (AUC) was calculated to evaluate the predictive ability of the variables examined. All analyses were performed using SPSS version 26.0 statistical software. A 2-tailed P value of $<0.05$ was regarded as statistically significant. Due to lack of distribution data of total serum IgE 4-week-tobaseline ratio levels in asthma patients after omalizumab treatment, power of test rather than intended sample size was calculated using PASS version 11.0 statistical software.

\section{Results}

\section{Response to omalizumab treatment}

All 25 patients were treated with omalizumab for 16 weeks, and most patients had an effective response to treatment. After 16 weeks of treatment, 4 patients (16\%) had an excellent response and $16(64 \%)$ a good response; 5 patients $(20 \%)$ showed no response. There were no significant differences in demographic and baseline clinical characteristics between responders and non-responders (Table 1). Lung function tended to be improved in responders. Oral corticosteroids could be withdrawn in 4 of the 5 responders who had been on oral corticosteroids before the study. Inhaled corticosteroid (ICS) doses were unchanged in all patients. The baseline ACT and ACQ scores in responders were $17.2 \pm 3.8$ and $2.2 \pm 1.1$, respectively. And the baseline ACT and ACQ scores in non-responders was $19.2 \pm 4.6$ and $1.4 \pm 1$, respectively. After 16 weeks of treatment, the average increase of ACT score was 3.7 and the average reduction of ACQ score was 1.4 in responders (both, $\mathrm{P}<0.01$ ). In contrast, there was no clinically relevant improvement in the non-responders (Table 2).

\section{Increases in IgE levels in responders and non-responders during the first 4 weeks}

At week 4 after beginning treatment, responders exhibited a significant increase in total $\mathrm{IgE}$ levels; whereas there was no change in levels in non-responders (Table 2, Figure 2).

\section{Predicting response to omalizumab treatment}

There were no significant difference in baseline total serum $\operatorname{IgE}$ level and total serum $\operatorname{IgE}$ level at week 4 between responders and non-responders (Table 3).

However, the week $4 \mathrm{IgE}$ level:baseline level ratio exhibited an AUC $=0.87$ (95\% CI: 0.64-1) for predicting a response to omalizumab treatment (Figure 3). The best ratio cutoff value ranged from 1.6 to 2.2; thus, for subsequent analysis a cutoff value of 2 was used. Using a cutoff value of 2 , the week $4 \mathrm{IgE}$ level:baseline level ratio exhibited a sensitivity of $100 \%$ and specificity of $80 \%$ for predicting a response to omalizumab (Figure 3). With $\alpha=0.05$, 21 patients' week $4 \mathrm{IgE}$ level:baseline level ratio over 2, 4 patients' week $4 \mathrm{IgE}$ level:baseline level ratio below 2, and an AUC of 0.87, the power of the test is 0.75 .

Twenty of 21 patients with a week $4 \mathrm{IgE}$ level:baseline level ratio $\geq 2$ were responders, while 4 of 4 patients with a ratio $<2$ were non-responders (at week 16).

\section{Serum vitamin D level and other markers for predicting response to omalizumab}

There were no differences in baseline FeNO, eosinophilic ratio in induced sputum, eosinophils in blood and blood eosinophil ratio, and serum vitamin $\mathrm{D}$ levels between responders and non-responders (Table 1).

\section{Discussion}

To our knowledge, this is the first study that has indicated that a more than 2 -fold increase in the week 4 serum $\operatorname{IgE}$ :baseline $\mathrm{IgE}$ ratio can predict a good/excellent response to omalizumab in patients with moderate-to-severe asthma. Our findings proved once again that omalizumab can improve overall asthma control; at the end of 16 weeks of treatment $80 \%$ of patients benefited from omalizumab, which is similar to the results of another real-life study of 158 patients rated by GETE (22). More importantly, our 
Table 1 Demographic and baseline clinical characteristics of study participants

\begin{tabular}{|c|c|c|c|c|}
\hline & All patients $(n=25)$ & Responder $(n=20)$ & Non-responder $(n=5)$ & $\mathrm{P}$ \\
\hline Female sex ${ }^{b}[n, \%]$ & $11[44]$ & $10[50]$ & $1[20]$ & 0.341 \\
\hline Total serum $\lg \mathrm{E}^{\mathrm{c}}(\mathrm{IU} / \mathrm{mL})$ & $210(85.0-349.1)$ & $224.1(94.34-324.1)$ & $207.7(61.20-669.4)$ & 0.838 \\
\hline Height $(\mathrm{cm})^{\mathrm{a}}$ & $163 \pm 8$ & $162.1 \pm 7.1$ & $166.4 \pm 11.1$ & 0.449 \\
\hline BMI $\left(\mathrm{kg} / \mathrm{m}^{2}\right)^{\mathrm{a}}$ & $23.1 \pm 3.4$ & $23.7 \pm 3.5$ & $20.8 \pm 1.3$ & 0.1 \\
\hline FEV1 (L) ${ }^{\mathrm{a}}$ & $2 \pm 0.8$ & $1.6 \pm 7.5$ & $2.5 \pm 1$ & 0.110 \\
\hline FEV $1 \%^{a}$ & $67.8 \pm 19.1$ & $64.8 \pm 19.6$ & $78.6 \pm 13.7$ & 0.156 \\
\hline FeNO $(p p b)^{c}$ & $35.5(18-62.25)$ & 36 [18-64] & $35(16-46.5)$ & 0.413 \\
\hline Eosinophilic ratio in sputum (EOS\%) ${ }^{c}$ & $2.5(0-19.5)$ & $3(0.5-33.5)$ & $2(0-24.5)$ & 0.5 \\
\hline Vitamin $\mathrm{D}(\mathrm{ng} / \mathrm{mL})^{\mathrm{c}}$ & $16.5(12-20.9)$ & $17.3(12.4-21.8)$ & $15.6(10.8-17.7)$ & 0.16 \\
\hline $\mathrm{ACT}^{\mathrm{a}}$ & $17.6 \pm 4$ & $17.2 \pm 3.8$ & $19.2 \pm 4.6$ & 0.323 \\
\hline$A C Q^{a}$ & $2 \pm 1.1$ & $2.2 \pm 1.1$ & $1.4 \pm 1$ & 0.137 \\
\hline $\begin{array}{l}\text { Inhaled corticosteroids } \\
(\mu \mathrm{g} / \mathrm{day})^{\mathrm{c}}\end{array}$ & 800 [400-900] & 600 [400-800] & $800[300-1,000]$ & 0.772 \\
\hline Use of oral corticosteroids [n, \%] & $6[24]$ & 5 [25] & $1[20]$ & 1 \\
\hline Omalizumab dose $(\mathrm{mg} / \mathrm{month})^{\mathrm{c}}$ & 300 [150-375] & 300 [150-412.5] & 300 [150-375] & 0.8 \\
\hline
\end{tabular}

Values are mean \pm standard deviation or median (interquartile range) unless cases and percentages. Values are those recorded at baseline. The doses of inhaled corticosteroid were converted to the equivalent dose of beclomethasone dipropionate. ${ }^{a}$, two-sample $t$-test; ${ }^{b}$, Fisher exact test; ' , Mann-Whitney U test. BMI, body mass index; FEV1, forced expiratory volume in $1 \mathrm{~s}$; FEV1\%, FEV1 percentage of predicted; FeNO, fractional exhaled nitric oxide; EOS\%, eosinophilic percentage of leukocyte; ACT, asthma control test; ACQ, asthma control questionnaire; ACO, asthma-COPD overlap.

results suggest a method to determine which patients will respond, i.e., the week 4:baseline $\operatorname{IgE}$ ratio may be useful for predicting patients who will respond to omalizumab within the first 16 weeks of treatment. Use of the ratio may help in deciding to continue or discontinue treatment.

During the first 4 weeks of treatment, the $\operatorname{IgE}$ levels of omalizumab responders increased, while that of nonresponders did not change. The underlying mechanisms for these findings are not clear and further research is needed. One of the possible reasons could be that the free $\operatorname{IgE}$ of non-responder doesn't combine with omalizumab. An antidrug antibody (ADA) response, off-target binding, and glycosylation pattern can inhibit the binding of omalizumab and $\operatorname{IgE}(23)$. A lack of complex formation can result in faster clearance of $\operatorname{IgE}$ and no increase in levels and a poor therapeutic effect in non-responders. In addition, omalizumab-IgE complexes may not be inactive and can capture allergens, which may improve the therapeutic effects of omalizumab (24).

In a prospective study including 41 severe asthmatics, serum IgE levels were measured over 1 year at 7 time points, and the results showed that there was limited within-patient variability of $\mathrm{IgE}$ levels (25). This finding suggests that measurement of total $\mathrm{IgE}$ is a stable method to determine management. Also, in our study serum IgE levels were not measured during an exacerbation of asthma. 
Table 2 The changes of clinical parameters in responder and non-responders

\begin{tabular}{|c|c|c|c|}
\hline & Responder $(n=20)$ & Non-responder $(n=5)$ & $\mathrm{P}^{\mathrm{a}}$ (responder vs. non-responder) \\
\hline \multicolumn{4}{|l|}{ Change: week 4 vs. baseline } \\
\hline Total serum IgE (Increase, \%) ${ }^{a}$ & $206.3(172.63-298.8)$ & $-4(-13.2$ to 126.2$)$ & 0.012 \\
\hline \multicolumn{4}{|l|}{ Change: week 16 vs. baseline } \\
\hline FEV1 $(L)^{b}$ & $0.5 \pm 0.7$ & $-0.05 \pm 0.3$ & 0.219 \\
\hline $\mathrm{ACT}^{\mathrm{b}}$ & $3.7 \pm 3.8$ & $0.8 \pm 1.3$ & 0.002 \\
\hline $\mathrm{ACQ}^{\mathrm{b}}$ & $-1.4 \pm 0.9$ & $-0.4 \pm 0.5$ & 0.006 \\
\hline GETE & Excellent, 4; good, 16 & Moderate, 4; poor, 1 ; worsened, 0 & - \\
\hline
\end{tabular}

${ }^{a}$, Mann-Whitney $\mathrm{U}$ test; ${ }^{\mathrm{b}}$, Two-sample t-test. Values are mean \pm standard deviation or median (interquartile range) unless cases. FEV1, forced expiratory volume in $1 \mathrm{~s}$; FEV1\%, FEV1 percentage of predicted; ACT, asthma control test; ACQ, asthma control questionnaire; GETE, global treatment effectiveness.

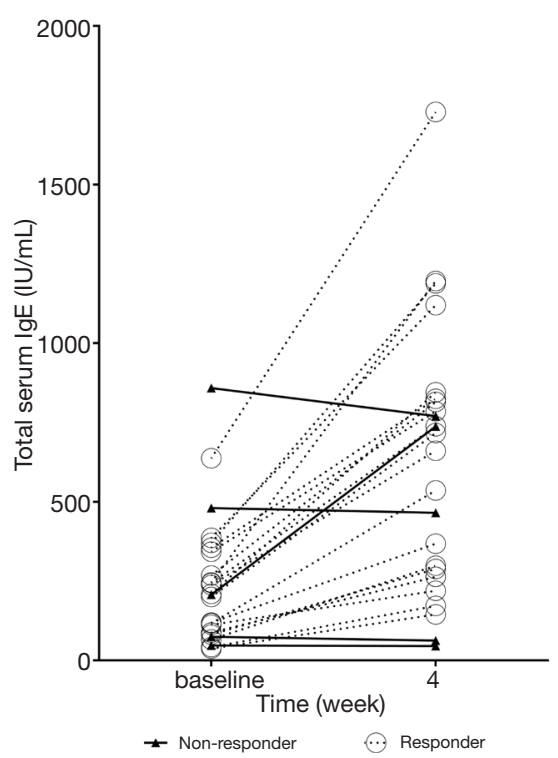

Figure 2 Baseline and week 4 total immunoglobulin E (IgE) levels in omalizumab treatment responders and non-responders.

However, during and after a severe exacerbation of asthma, serum $\mathrm{IgE}$ level may increase and may remain elevated for 1-2 months. Thus, total IgE levels should not be measured for 4-8 weeks after an exacerbation if they are going to be used to guide management (26).

In this study, we used GETE to measure treatment effectiveness. GETE is widely used for evaluating the response to omalizumab effectiveness $(22,27)$. Most prior reports have evaluated responsiveness to omalizumab by monitoring a decrease of asthma exacerbations or an improvement in asthma quality of life questionnaire (AQLQ) score $(15,28)$.

Our results showed that response to omalizumab cannot be predicted by blood eosinophil count, which is similar to the results of other studies $(12,27)$.

GINA 2020 (4) and some other studies $(12,15)$ have indicated that asthma patients with high FeNO levels are more likely to respond to omalizumab. Other studies, however, have arrived at opposite conclusions (28).

In this study, 3 patients with ACO (asthma-COPD overlap) had good treatment responses; this finding is consistent with that of a recent a large-scale, real-world study that indicated patients with ACO treated with omalizumab had similar clinical outcomes to patients with asthma without ACO in terms of improvements in exacerbation frequency and ACT score (29). Usually, high levels of $\mathrm{IgE}$ and FeNO, and a high blood eosinophil count are markers of a better response to omalizumab for ACO patients (30).

Vitamin D insufficiency is common in asthmatics, and low vitamin D levels are associated with asthma severity and higher odds of asthma exacerbation (31-33). Therefore, we also investigate the predictive value of vitamin $\mathrm{D}$ in treatment response of omalizumab. Our results showed that baseline Vitamin D levels cannot predict response to omalizumab.

Several limitations of this study need to be emphasized. First, the sample size was small; we plan to perform a future investigation with a larger number of patients. Second, we did not examine allergic responses with a specific serum IgE or skin prick test; however, some studies have shown that 
Table 3 Levels of baseline and week $4 \mathrm{IgE}$, week 4/baseline $\operatorname{IgE}$, and increases in $\operatorname{IgE}$ levels in patients who show response or no response at week 16 of omalizumab treatment

\begin{tabular}{|c|c|c|c|c|}
\hline & All patients $(n=25)$ & Responder $(n=20)$ & Non-responder $(n=5)$ & $\mathrm{P}^{\mathrm{a}}$ \\
\hline Week $4 \lg E(I U / m L)$ & $660.9(276.3-820.1)$ & $689.2(291.2-840.4)$ & $669.4(54.3-754.4)$ & 0.174 \\
\hline The week 4:baseline IgE ratio & $3(2.3-3.7)$ & $3.1(2.7-4)$ & $1(0.9-2.3)$ & 0.012 \\
\hline
\end{tabular}

All values are median (interquartile range). ${ }^{a}$, Mann-Whitney $U$ test was used.

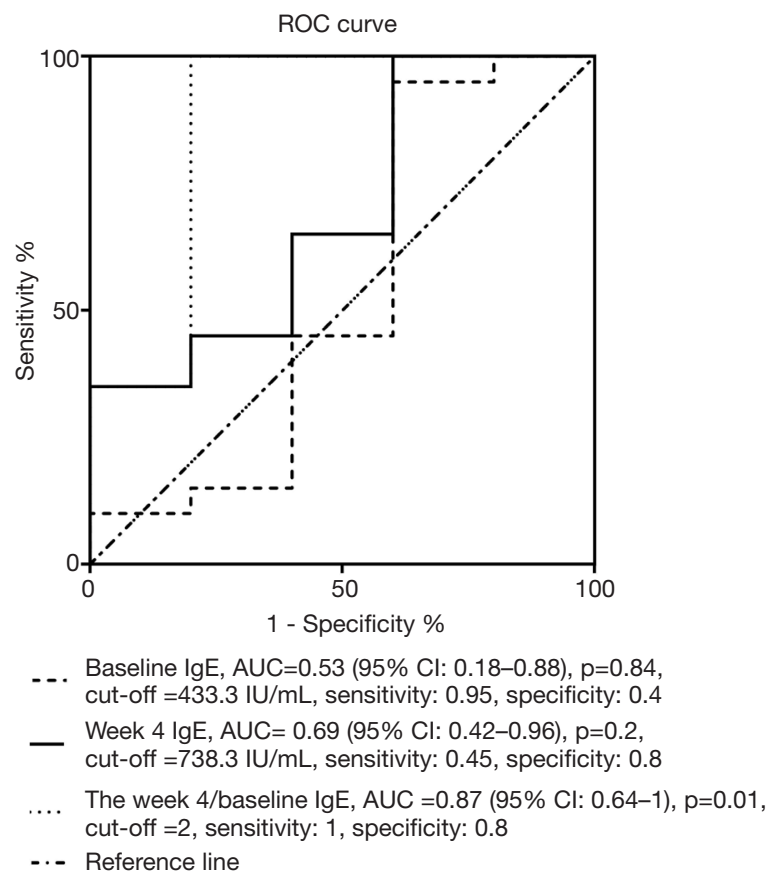

Figure 3 Predictive value of baseline IgE, week 4 immunoglobulin $\mathrm{E}(\mathrm{IgE})$, and the week 4:baseline $\operatorname{IgE}$ ratio for predicting the response to omalizumab at 16 weeks. The values in brackets are $95 \%$ CIs.

omalizumab can be effective in non-atopic severe asthma $(34,35)$. Third, it cannot be excluded that the number of responders will increase with an increasing duration of treatment. However, it seems that the effectiveness after 16 weeks is similar to that of an extended course of treatment. A study of 258 patients demonstrated that the GETE at 16 weeks in omalizumab-treated asthma patients is an effective indicator of a persistent response, and could predict treatment response or nonresponse at week 32 in $83.3 \%$ of patients (36). Lastly, this study was not blinded and patients were aware of their total IgE levels.

\section{Conclusions}

The study showed that a week 4:baseline $\operatorname{IgE}$ ratio $\geq 2$ predicts a good response to omalizumab at 16 weeks in patients with moderate-to-severe asthma. Future multicenter trials with a large sample size are required to verify the results.

\section{Acknowledgments}

The authors would like to thank the patients and others who cooperated in performing this study.

Funding: This work was supported by the Precision Medicine Research of The National Key Research and Development Plan of China (2016YFC0905800), the National Natural Science Foundation of China (81770033, 81670026, 81700034, 81870026), the Scientific and Technological Project of Guangdong Province (2016A020215117, 2017B020226006, 201804010069) and the Science and Technology Program of Guangzhou, China (201804010069).

\section{Footnote}

Data Sharing Statement: Available at http://dx.doi. org/10.21037/jtd-20-2073

Conflicts of Interest: All authors have completed the ICMJE uniform disclosure form (available at http://dx.doi. org/10.21037/jtd-20-2073). The authors have no conflicts of interest to declare.

Ethical Statement: The authors are accountable for all aspects of the work in ensuring that questions related to the accuracy or integrity of any part of the work are appropriately investigated and resolved. The study was conducted in accordance with the Declaration of Helsinki 
(as revised in 2013). This study was approved by the Ethics Committee of Nanfang Hospital, Southern Medical University (code number NFEC-2018-092). All adult subjects and the parents of children patients have given their written informed consent prior to participation in the study.

Open Access Statement: This is an Open Access article distributed in accordance with the Creative Commons Attribution-NonCommercial-NoDerivs 4.0 International License (CC BY-NC-ND 4.0), which permits the noncommercial replication and distribution of the article with the strict proviso that no changes or edits are made and the original work is properly cited (including links to both the formal publication through the relevant DOI and the license). See: https://creativecommons.org/licenses/by-nc-nd/4.0/.

\section{References}

1. Gould HJ, Sutton BJ. IgE in allergy and asthma today. Nat Rev Immunol 2008;8:205-17.

2. Balbino B, Conde E, Marichal T, et al. Approaches to target $\mathrm{IgE}$ antibodies in allergic diseases. Pharmacol Ther 2018;191:50-64.

3. Chung KF. Anti-IgE monoclonal antibody, omalizumab: a new treatment for allergic asthma. Expert Opin Pharmacother 2004;5:439-46.

4. Global strategy for asthma management and prevention: Updated 2020. Available online: http://ginasthma.org

5. Liu J, Lester P, Builder S, et al. Characterization of complex formation by humanized anti-IgE monoclonal antibody and monoclonal human $\mathrm{IgE}$. Biochemistry 1995;34:10474-82.

6. Chapman KR, Cartier A, Hébert J, et al. The role of omalizumab in the treatment of severe allergic asthma. Can Respir J 2006;13 Suppl B:1B-9B.

7. MacGlashan DW Jr, Bochner BS, Adelman DC, et al. Down-regulation of Fc(epsilon)RI expression on human basophils during in vivo treatment of atopic patients with anti-IgE antibody. J Immunol 1997;158:1438-45.

8. Holgate S, Buhl R, Bousquet J, et al. The use of omalizumab in the treatment of severe allergic asthma: A clinical experience update. Respir Med 2009; 103:1098-113.

9. Bousquet J, Cabrera P, Berkman N, et al. The effect of treatment with omalizumab, an anti-IgE antibody, on asthma exacerbations and emergency medical visits in patients with severe persistent asthma. Allergy
2005;60:302-8.

10. Korn S, Thielen A, Seyfried S, et al. Omalizumab in patients with severe persistent allergic asthma in a real-life setting in Germany. Respir Med 2009;103:1725-31.

11. Lanier BQ. Unanswered questions and warnings involving anti-immunoglobulin E therapy based on 2-year observation of clinical experience. Allergy Asthma Proc 2005;26:435-9.

12. Suzukawa M, Matsumoto H, Ohshima N, et al. Baseline serum CXCL10 and IL-12 levels may predict severe asthmatics' responsiveness to omalizumab. Respir Med 2018;134:95-102.

13. Bousquet J, Wenzel S, Holgate S, et al. Predicting response to omalizumab, an anti-IgE antibody, in patients with allergic asthma. Chest 2004;125:1378-86.

14. Korn S, Haasler I, Fliedner F, et al. Monitoring free serum $\mathrm{IgE}$ in severe asthma patients treated with omalizumab. Respir Med 2012;106:1494-500.

15. Hanania NA, Wenzel S, Rosen K, et al. Exploring the effects of omalizumab in allergic asthma: an analysis of biomarkers in the EXTRA study. Am J Respir Crit Care Med 2013;187:804-11.

16. Ertas R, Ozyurt K, Atasoy M, et al. The clinical response to omalizumab in chronic spontaneous urticaria patients is linked to and predicted by IgE levels and their change. Allergy 2018;73:705-12.

17. Expert Group of Omalizumab for Allergic Asthma CMARBAG. Chinese expert consensus on omazumab for allergic asthma. Chinese Journal of Tuberculosis and Respiratory Diseases 2018;41:179-85.

18. Chung KF, Wenzel SE, Brozek JL, et al. International ERS/ATS guidelines on definition, evaluation and treatment of severe asthma. Eur Respir J 2014;43:343-73.

19. Price D. The use of omalizumab in asthma. Prim Care Respir J 2008;17:62-72.

20. Juniper EF, O'Byrne PM, Guyatt GH, et al. Development and validation of a questionnaire to measure asthma control. Eur Respir J 1999;14:902-7.

21. Nathan RA, Sorkness CA, Kosinski M, et al. Development of the asthma control test: a survey for assessing asthma control. J Allergy Clin Immunol 2004;113:59-65.

22. Brusselle G, Michils A, Louis R, et al. "Real-life" effectiveness of omalizumab in patients with severe persistent allergic asthma: The PERSIST study. Respir Med 2009;103:1633-42.

23. Matera MG, Calzetta L, Rogliani P, et al. Monoclonal antibodies for severe asthma: Pharmacokinetic profiles. Respir Med 2019;153:3-13. 
24. Hsu CL, Shiung YY, Lin BL, et al. Accumulated immune complexes of $\mathrm{IgE}$ and omalizumab trap allergens in an in vitro model. Int Immunopharmacol 2010;10:533-9.

25. Louis R, Pilette C, Michel O, et al. Variability in total serum IgE over 1 year in severe asthmatics. Allergy Asthma Clin Immunol 2019;15:20.

26. Semprini R, Shortt N, Ebmeier S, et al. Change in biomarkers of type-2 inflammation following severe exacerbations of asthma. Thorax 2019;74:95-8.

27. Bousquet J, Rabe K, Humbert M, et al. Predicting and evaluating response to omalizumab in patients with severe allergic asthma. Respir Med 2007;101:1483-92.

28. Busse W, Corren J, Lanier BQ, et al. Omalizumab, anti$\mathrm{IgE}$ recombinant humanized monoclonal antibody, for the treatment of severe allergic asthma. J Allergy Clin Immunol 2001;108:184-90.

29. Hanania NA, Chipps BE, Griffin NM, et al. Omalizumab effectiveness in asthma-COPD overlap: Post hoc analysis of PROSPERO. J Allergy Clin Immunol 2019;143:162933.e2.

Cite this article as: $\mathrm{Li} \mathrm{B}$, Huang $M$, Huang S, Zeng $\mathrm{X}$, Yuan Y, Peng X, Zhao W, Ye Y, Yu C, Liu L, Ou C, Cai S, Zhao H. Prediction of clinical response to omalizumab in moderateto-severe asthma patients using the change in total serum IgE level. J Thorac Dis 2020;12(12):7097-7105. doi: 10.21037/jtd20-2073
30. Sposato B, Scalese M, Milanese M, et al. Should omalizumab be used in severe asthma/COPD overlap? J Biol Regul Homeost Agents 2018;32:755-61.

31. de Groot JC, van Roon EN, Storm H, et al. Vitamin D reduces eosinophilic airway inflammation in nonatopic asthma. J Allergy Clin Immunol 2015;135:670-5.e3.

32. Korn S, Hübner M, Jung M, Blettner M, et al. Severe and uncontrolled adult asthma is associated with vitamin D insufficiency and deficiency. Respir Res 2013;14:25

33. Salas NM, Luo L, Harkins MS, et al. Vitamin D deficiency and adult asthma exacerbations. J Asthma. 2014;51:950-5

34. de Llano LP, Vennera MC, Alvarez FJ, et al. Effects of omalizumab in non-atopic asthma: results from a Spanish multicenter registry. J Asthma 2013;50:296-301.

35. Çelebi Sözener Z, Aydın Ö, Mısırlıgil Z, et al. Omalizumab in non-allergic Asthma: A report of 13 cases. J Asthma 2018;5 5:756-63.

36. Bousquet J, Siergiejko Z, Świebocka E, et al. Persistency of response to omalizumab therapy in severe allergic ( $\mathrm{IgE}$ mediated) asthma. Allergy 2011;66:671-8. 